\title{
Design and Analysis of Neuro Fuzzy Logic PD Controller for PWM-Based Switching Converter
}

\author{
Faridoon Shabaninia*, Shadi Pouyanfar, Seyed Hamidreza Abbasi \\ School of Electrical and Computer Engineering, Shiraz University, Iran \\ *Corresponding Author: shabani@shirazu.ac.ir
}

Copyright (C) 2014 Horizon Research Publishing All rights reserved.

\begin{abstract}
This paper describes the Neuro-Fuzzy logic based controller design for the buck DC-DC converters. As it is obvious form the previous type of controllers (conventional PID) for such converters which have been designed under the worst case condition for high load and lowest line condition, they present a lower loop in band width, and the system response is sluggish. In this regard, since the neural networks have powerful learning capabilities, optimization abilities, and adaptation, in this paper the design and analysis for a Neuro-Fuzzy PWM based PD controller is proposed. Lastly, In order to show that the Neuro logic based PD controller provides robust control for non-linear power electronics variable switching structure such as the dc-dc buck converter, MATLAB Simulink software is employed to confirm the corresponding results validity.
\end{abstract}

Keywords Neuro Fuzzycontroller, PD Controller, PWM-Switching Convertor, DC-DC Buck Convertor

\section{Introduction}

Voltage regulation for dc-dc converters has traditionally been accomplished using analog control concepts. The interest is beginning to develop in the application of digital control principles to this regulation function. In DC-DC converters, due to unspecified transfer function, employing of the fuzzy controllers could be impressive and beneficial. The behavior of DC-DC converters around the operation point can be linearly modeled and the controller can be designed by using the linear control conceptions such as PI and PID controllers, etc. To design the controller, the transfer function of converters are needed which is usually a complicated task.

With fuzzy control, the design concept is totally different. The operation of fuzzy controller does not rely on how accurate the model is, but on how effective the linguistic rules of the fuzzy controller are. A Perfect Fuzzy control therefore simplifies the design of optimal compensation for DC-DC converters.
Since fuzzy control is based on heuristic rules, it facilitates the application of non-linear control laws to face the nonlinear nature of dc-dc converters.

\section{Fuzzy Logic}

\subsection{Fuzzy Logic Concept}

The philosophy of Fuzzy logic is besides the normal logical States: 0 and 1 which lead to states (membership values) between those. The grade of membership can be regarded as the capability of belonging of the described linguistic term. Linguistic variables, defined as variables whose values are sentences in a natural language (such as small and large), may be represented by fuzzy sets. A fuzzy set is an extension of a crisp set, where a crisp element just can belong to a set (full membership) or not belong at all (no membership). Fuzzy sets allow partial membership, which means that an element may partially belong to more than one set. A fuzzy set A is identified by a membership function that assigns to each object in a given class a rate of membership to the set. Of course, the grade of membership can range from 0 to 1 ;

\subsection{Fuzzy Control}

Fuzzy control includes some steps which are common in most fuzzy control applications. First is determining input and output of the system. Second is fuzzification of input and output and then determine membership function for them. Process part of fuzzy controller design is to derive rules from expert knowledge, which will be used to assign rules. Last step is converting fuzzy value to its crisp value in defuzzification step.

\section{DC-DC Buck Convertor}

This chapter is focused on introduction of DC-DC converters. Hence, a typical schematic of a sample buck converter is represented bellow and the detail will be 
described later:

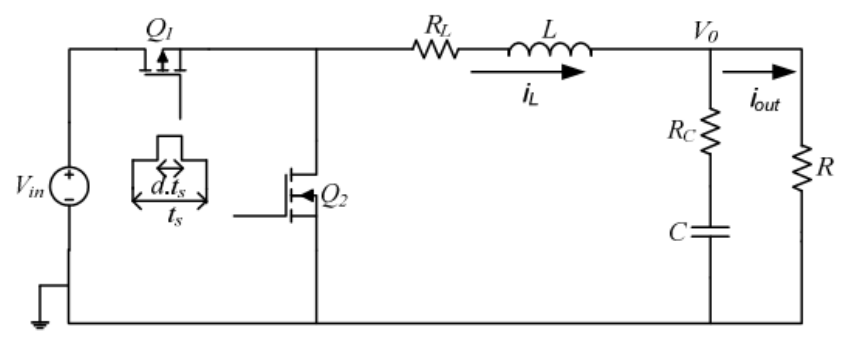

Figure 1. DC-DC converter schematic

As it shown Figure 1, there is DC voltage as input $\left(V_{\text {in }}\right)$ which its value is more than output voltage generally. One switching element (FET, GBT ...) will be used to guide input voltage to output in off time and close return path of input voltage toward source in on time. We can control duty cycle of on/off switching time as controller parameter. Pulse Width Modulation (PWM) signal is used to adjust output level in desired value. So we need controller to make corresponding duty cycle to cover input changes, load changes, non-linearity/change in elements and so on.

\section{Controller Design}
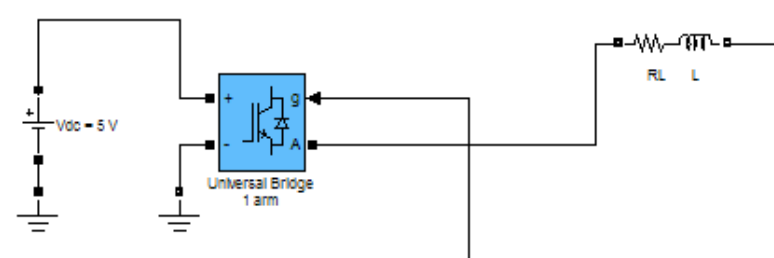

DC/DC Buck Converter
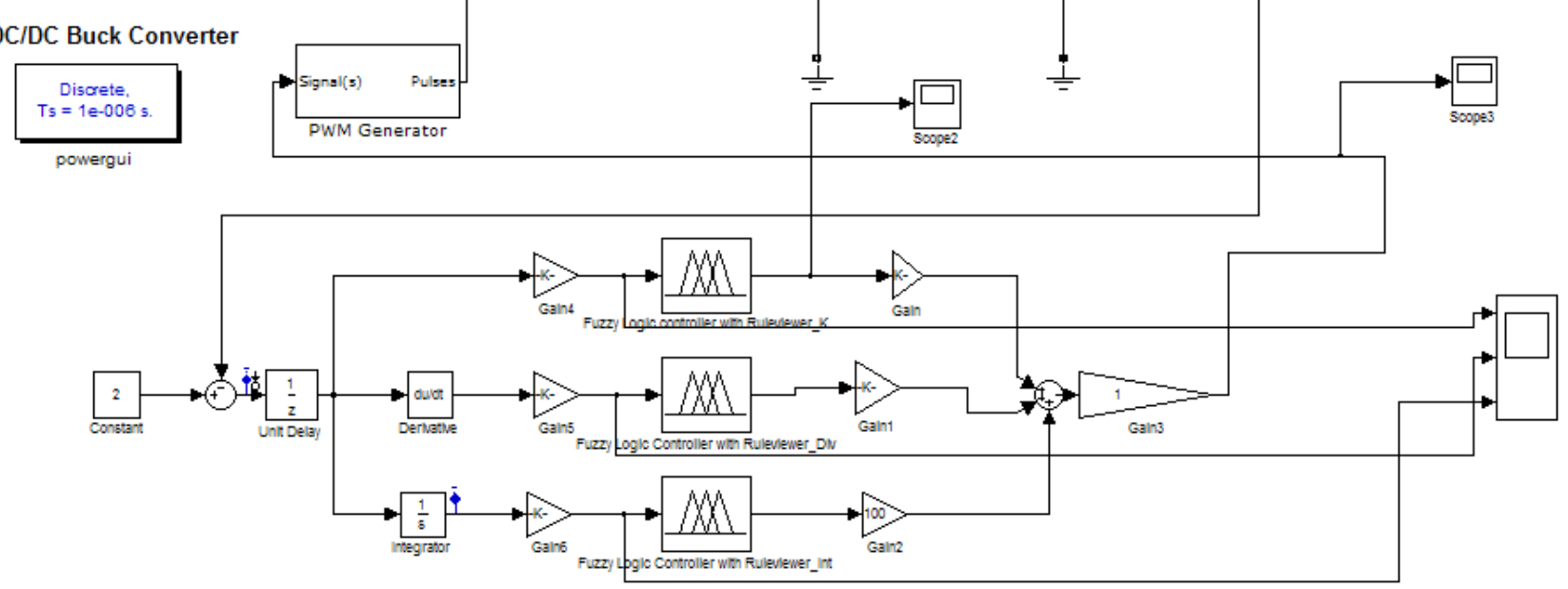

Figure 2. Fuzzy PID controller system

\subsection{Fuzzy PID Controller}

By using Buck DC-DC converter model, following system (Figure 2) is implemented to operate as PWM based PID controller. As it is depicted, three different parameters are used as the Fuzzy Logic Controller (FLC) inputs. They are including Error, Error Changes and Error Integral.

The parameters which are considered in the model are as $\mathrm{R}_{\mathrm{L}}=0.08 \Omega, \mathrm{L}=5 \mu H, \mathrm{R}_{\mathrm{C}}=0.005 \Omega, \mathrm{F}=305 \mu \mathrm{F}$ and $\mathrm{R}_{\mathrm{L}}=1 \Omega$. There are three levels of input membership functions are defined as Negative, Zero and Positive. Also, output membership functions have three levels as the same as inputs(Table 1), but the domain range is different in somehow.

Table 1. Rule table for fuzzy PID controller

\begin{tabular}{|c|c|c|}
\hline $\mathrm{Np}$ & $\mathrm{Ni}$ & $\mathrm{Nd}$ \\
\hline If $\mathrm{e}(\mathrm{k})=\mathrm{N}$ then $\mathrm{y}=\mathrm{N}$ & If $\mathrm{ie}(\mathrm{k})=\mathrm{N}$ then $\mathrm{y}=\mathrm{N}$ & If $\mathrm{de}(\mathrm{k})=\mathrm{N}$ then $\mathrm{y}=\mathrm{N}$ \\
\hline If $\mathrm{e}(\mathrm{k})=\mathrm{Z}$ then $\mathrm{y}=\mathrm{Z}$ & If $\mathrm{ie}(\mathrm{k})=\mathrm{Z}$ then $\mathrm{y}=\mathrm{Z}$ & If $\mathrm{de}(\mathrm{k})=\mathrm{Z}$ then $\mathrm{y}=\mathrm{Z}$ \\
\hline If $\mathrm{e}(\mathrm{k})=\mathrm{P}$ then $\mathrm{y}=\mathrm{P}$ & If $\mathrm{ie}(\mathrm{k})=\mathrm{P}$ then $\mathrm{y}=\mathrm{P}$ & If $\mathrm{de}(\mathrm{k})=\mathrm{P}$ then $\mathrm{y}=\mathrm{P}$ \\
\hline
\end{tabular}

By using MATLABsimulation, the corresponding response for this system can be achieved as bellow. Here, the desired output voltage value is considered as 2 Volts. (Figure 3). 


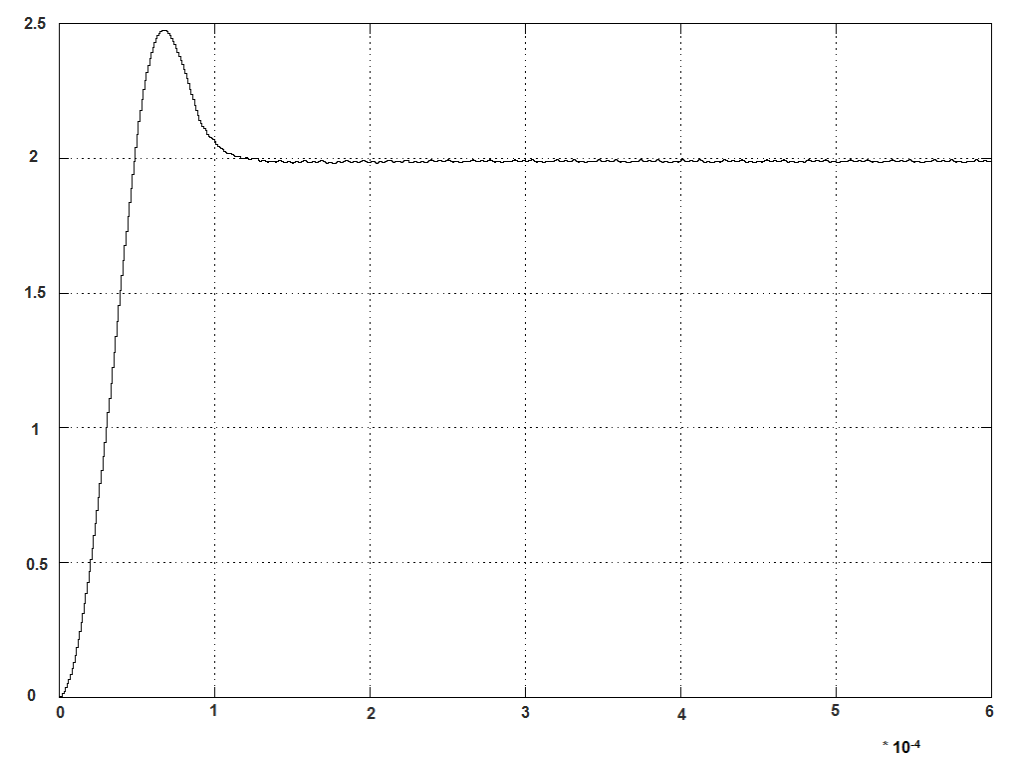

Figure 3. Output of Fuzzy PID

For optimizing the system response and to gain a better step response, it is needed to change the membership functions in anyhow. So, in this step seven levels for inputs and outputs membership functions are defined.

Therefore, the following values for each level could be regarded for above membership functions (Figure 4):

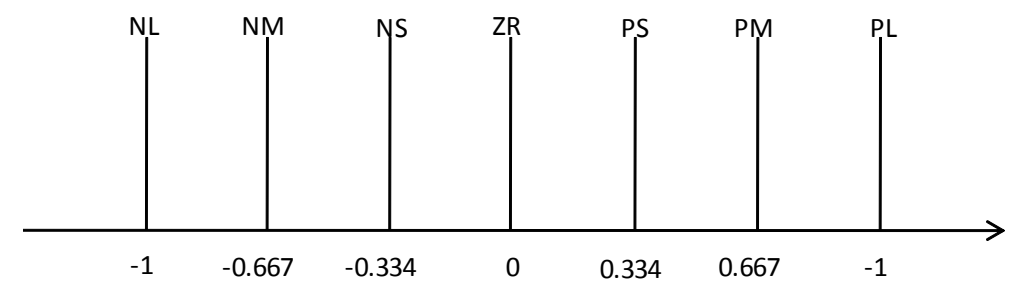

Figure 4. Definition of level value for membership function

Considering the increment in the level of inputs and outputs, it is expected to have smooth and more accurate output which is partially achieved (Figure 5).

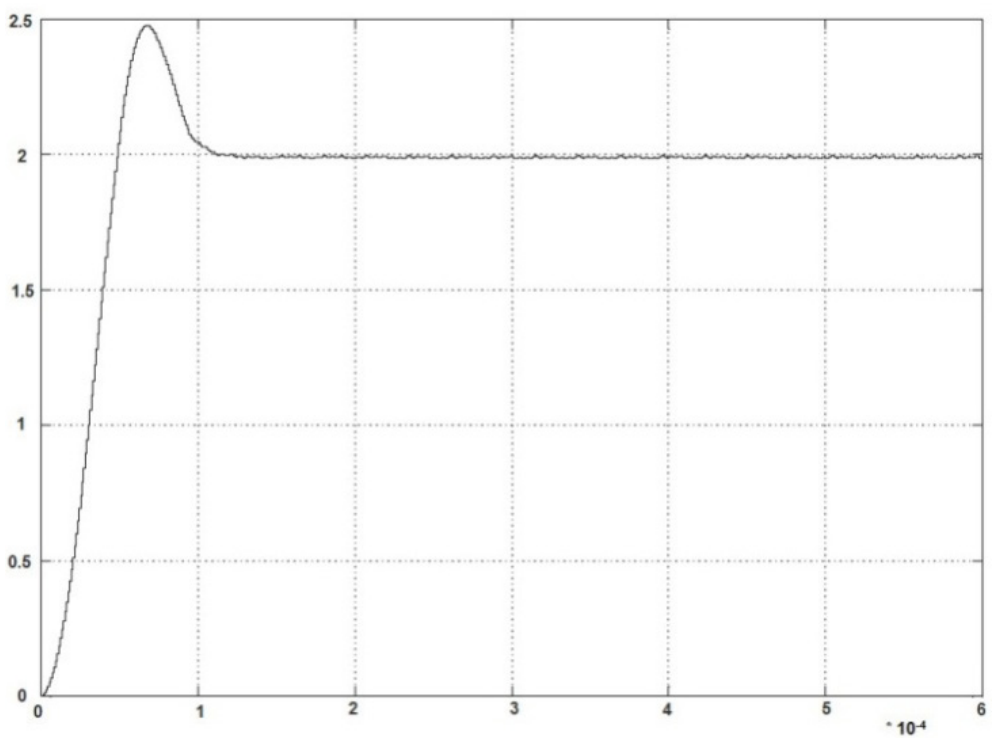

Figure 5. Output of Fuzzy PID with 7 level membership function system 


\subsection{Fuzzy PD Controller}

It is known that the Error signal and derive of error are parameters which can illustrate the system status. So, as it is depicted in the following figure 6, these two parameters are inserted to fuzzy module as its inputs in a same block, and therefore the input membership functions have two input functions and one output value.

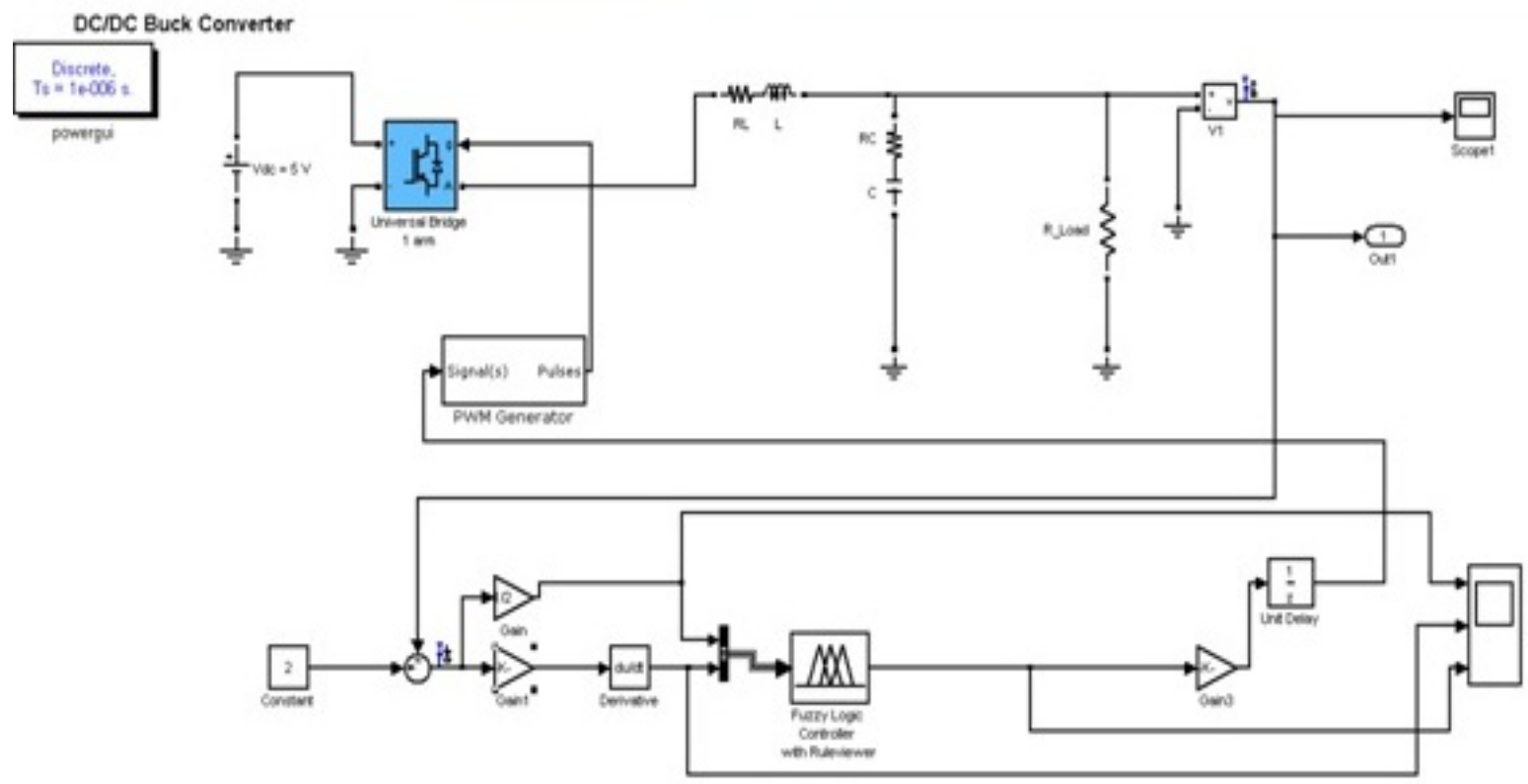

Figure 6. Fuzzy PD controller system schematic

In addition, the relative rules are shown in table 2. As it is obvious, the controller has seven different levels of inputs for $\mathrm{E}$ and $\operatorname{div}(\mathrm{E})$ which finally lead to define 49 rules.

Table 2. Fuzzy rules based on Error (e) and Div(Error)

\begin{tabular}{|cccccccc|}
\hline E/dE & NL & NM & NS & ZR & PS & PM & PL \\
\hline PL & ZR & PS & PM & PL & PL & PL & PL \\
PM & NS & ZR & PS & PL & PL & PL & PL \\
PS & NM & NS & ZR & PS & PM & PL & PL \\
ZR & NL & NM & NS & ZR & PS & PM & PL \\
NS & NL & NL & NM & NS & ZR & PS & PM \\
NM & NL & NL & NL & NM & NS & ZR & PS \\
NL & NL & NL & NL & NL & NM & NS & ZR \\
\hline
\end{tabular}

Moreover, the corresponding surface view for inputs and output is depicted in figure 7.

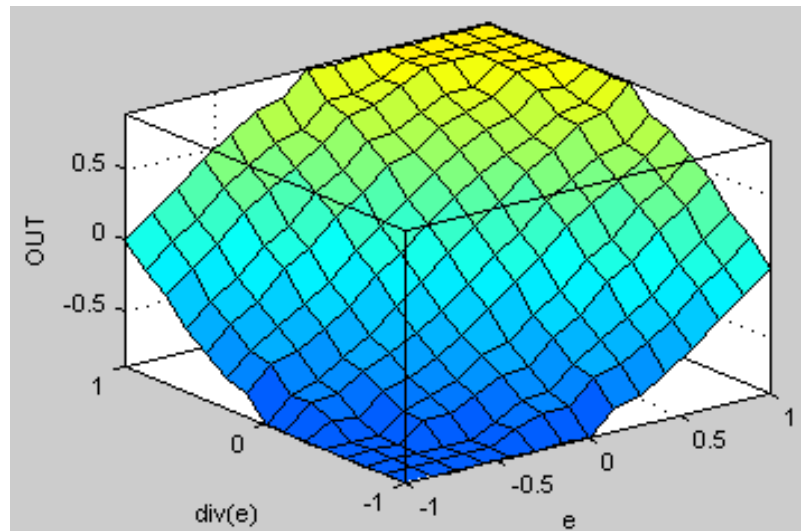

Figure 7. Surface view of PD controller rules 
On the other hand, the Fuzzy PD system output is shown in Figure 8, and as it illustrated X axis is belongs to time domain and $\mathrm{Y}$ axis shows output value in voltage.

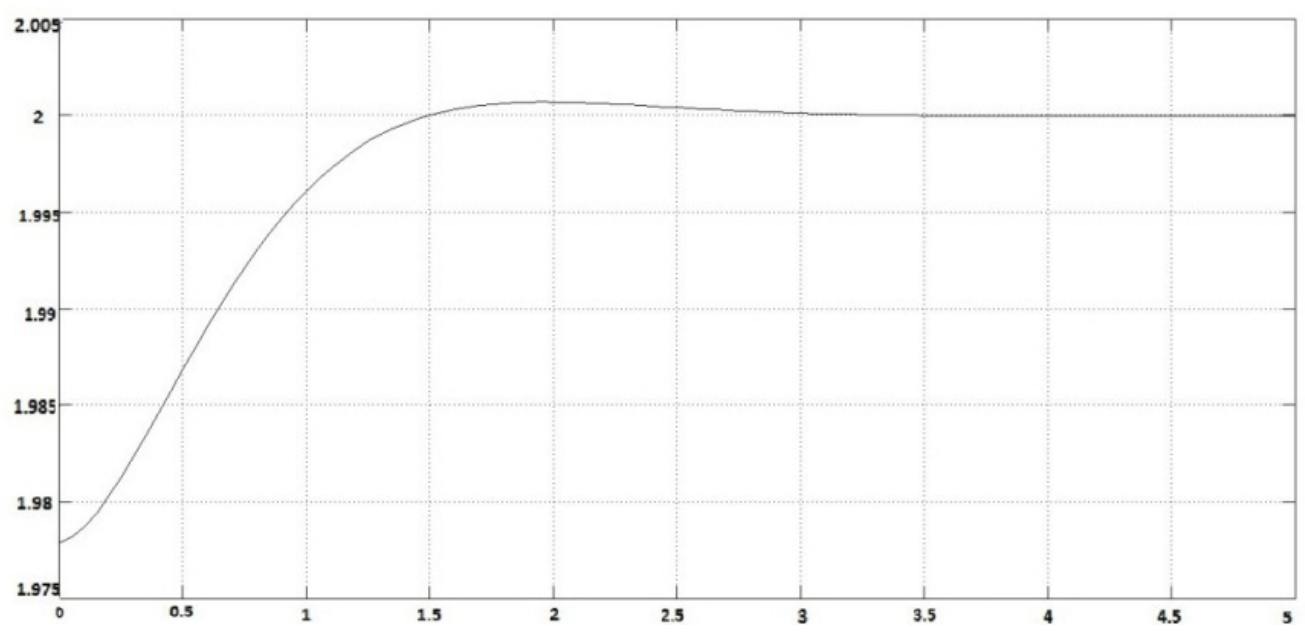

Figure 8. Fuzzy PD system output

\subsection{ANFIS}

As it is went in previous parts, a fuzzy PID with 3 level mfs, fuzzy PID with 7 level mfs and fuzzy PD controllers are employed and the corresponding results represented and compared to each other's. In the following section, it is purposed to apply a Neuro-Fuzzy PD controller system by employing MATLAB ANFIS Toolbox.

Using Error (e) and Error Derive $(\operatorname{div}(e))$, from previous section as inputs and pulse width as output, will lead to train neural network with train data.

As it illustrated in the following structure, a neural network with 2 inputs and 3 membership functions for each input is designed (Figure 9)

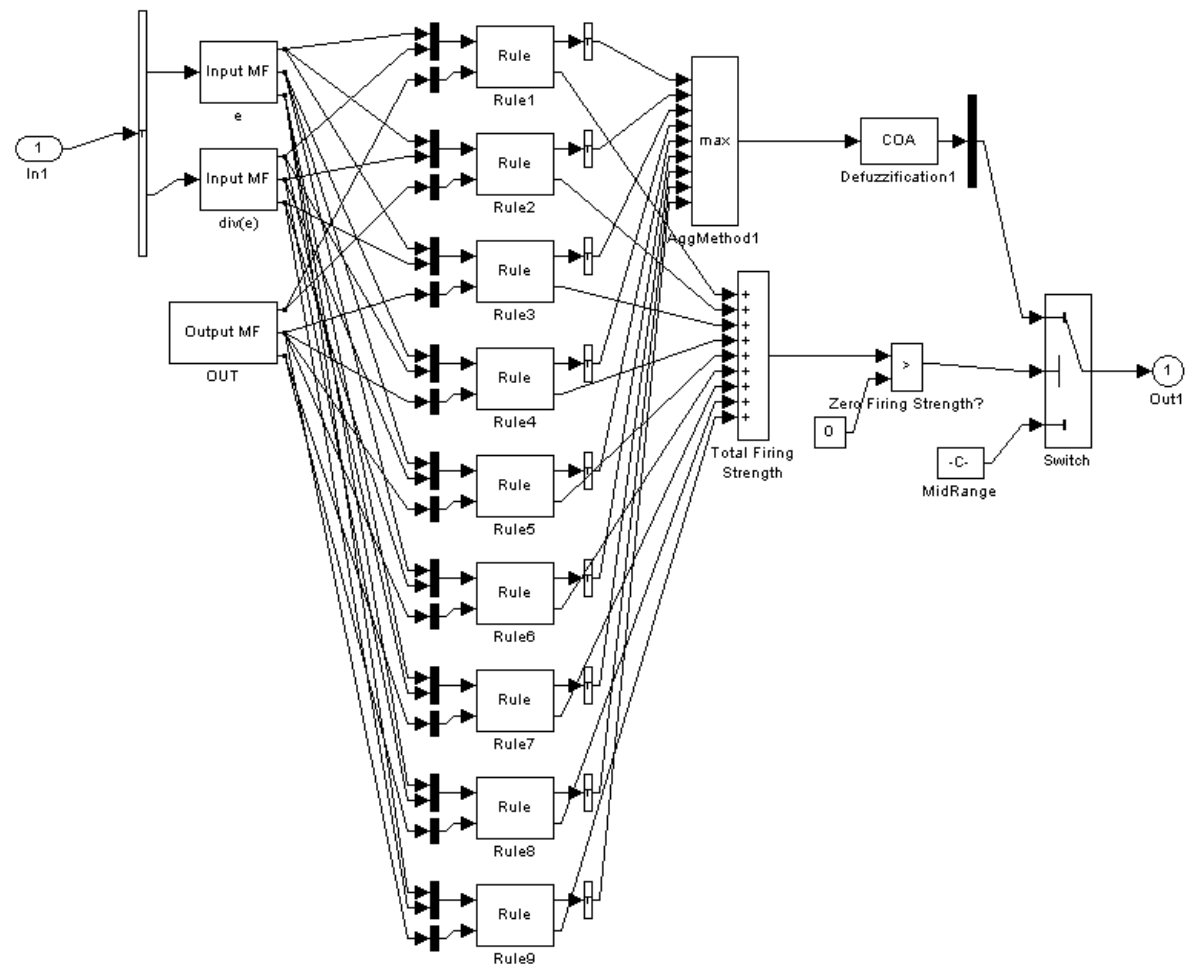

Figure 9. Neuro Fuzzy network structure

Here, the system is learned with fuzzy PD data, and the same output response for fuzzy PD method is achieved. As it is 
clear, the response is not optimized enough and a better response for the system is purposed (Figure 8)

In order to optimize the system response, it is aimed to modify learning data to decrease over shout and rise time. By having a good performance for the system(well-tuned conventional PID as instance), the corresponding inputs and output data could be used; otherwise, by knowing the desired system response and using statistical analyses on data, the required information and samples for learning neural network system can be prepared.

Data which achieved from well-tuned PID was used as ANFIS input. According to Figure 10 the result of learning was acceptable. After learning the system with desire system data, the improvement of the system response is clearly obvious (Figure 11).

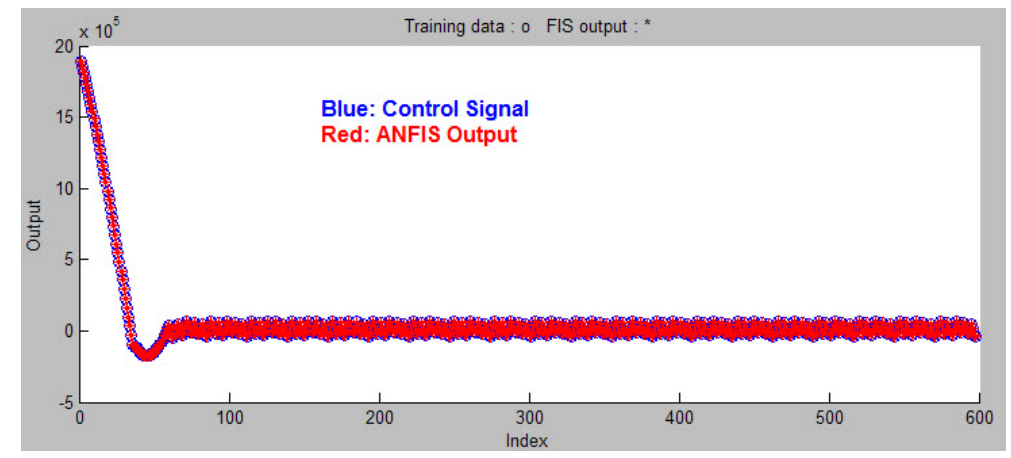

Figure 10. ANFIS Input data and learned neural network output compare

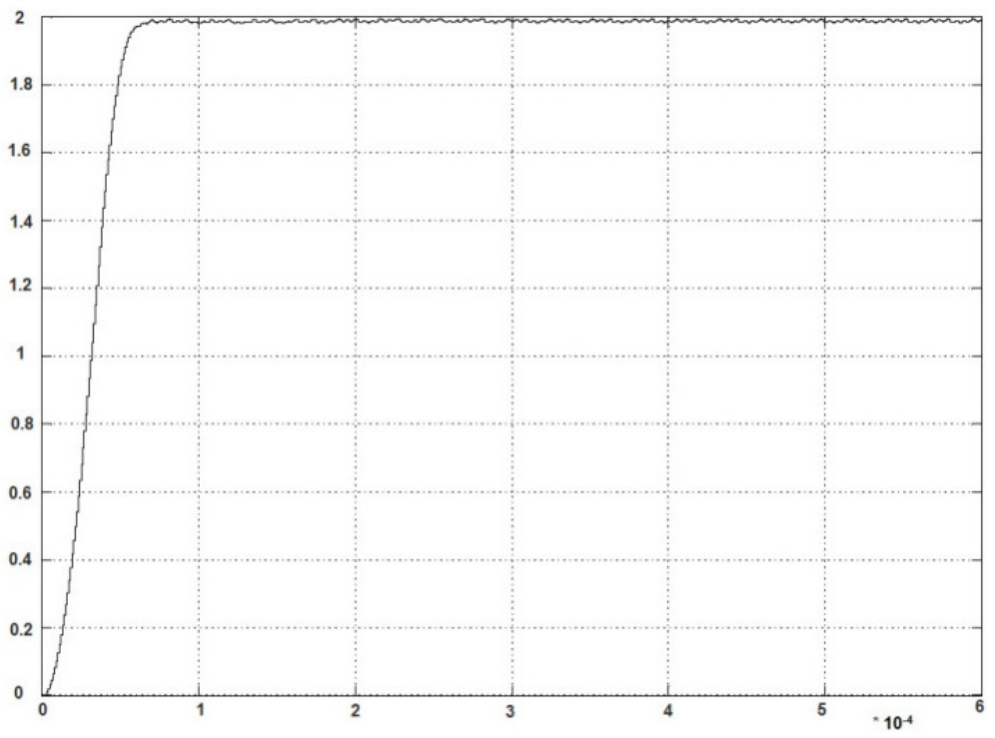

Figure 11. Neuro-Fuzzy PD controller output

\section{Conclusion}

It is resulted that an enhanced control could be regarded and achievable by using fuzzy control to a robust control onnonlinear systems or systems which cannot be controlled by classic controllers. It is clear that in Neuro design, there is noneed to have/design membership functions, but just to allocating the inputs and desired output is completely essential.

Fuzzy control method has lots of beneficial advantages and one of theimpressive merits can be mentioned as defining of the linguistic rules. On the other hand, one of the shortagesof this method is that the membership functions could not be defined completely by employing the classical design methods.
In addition, customized NN for fuzzy application can be considered as one of designing solutions. Using hybrid method including fuzzy and neural networks will leads to better learning rules mechanism of the system by means of training data.

Robust control achievement can be mentioned as a benefit in compare with previous methods. Independency of controller performance,to elements parameter, is the advantage which is gained by using ANFIS controller. This will lead to reducing effect of element value changes, Life environmental changes,

Finally, it is concluded that by employing Neuro PD ANFIS in comparison with pervious methods (such as fuzzy PID and fuzzy PD controllers), better results areachieved in the final system responses and also in the simulations.These 
results show the ease of applying fuzzy control to $\mathrm{dc} / \mathrm{dc}$ converters, as an interesting alternative to conventional techniques. Also, test results illustrate that the Neuro fuzzy logic approach can provide considerable control performances rather than other conventional methods.

\section{REFERENCES}

[1] P. C. Sen, "Electric motor drives and control—Past, present, andfuture", IEEE Trans. Ind. Electron., vol. 37, pp. 562-575, Dec. 1990.

[2] J.A.A. Qahouq, "On load adaptive control of voltage regulators forpower managed loads: control schemes to improve converter efficiencyand performance", IEEE Transactions on Power Electronics, Vol. 22,2007, pp. 1806 1819.

[3] S. Nithya, Abhay Singh Gour, N. Si vakumaran, T. K. Radhakrishnan, T. Balasubramanian, and N. Anantharaman, "Intelligent controller implementation in real time for a non linear process", IEEE International Symposium on Industrail Electronics, 2008, pp. 2508

[4] 2513.K. Lian, "LMI-based integral fuzzy control of DC-DC converters",IEEE Transactions on Fuzzy Systems, Vol. 14, 2006 , pp. $71-80$.

[5] M. Bayati Poodeh, S. Eshtehardiha and M.R.Zare, "Application of Fuuzy Logic to Control the DC-DC Converter", 7th WSEAS International Conference on Electric
Power Systems, High Voltages, Electric Machines, Venice, Italy, November 21-23, 2007.

[6] V.S.C Raviraj and P.C Sen., "Comparative study of proportional-integral, sliding mode, and Fuzzy Logic Controllers for power Converters", IEEE Transactions on Industry Applications, vol. 33, no. 2, March/April 1997.

[7] Isin Erenoglu, Ibrahim Eksin, Engin Yesil and Mujde Guzelkaya, "An Intelligent Hybrid Fuzzy PID Controller", Proceedings 20th European Conference on Modelling and Simulation, ECMS, 2006.

[8] J. Mahdavi, A. Emadi, H. A. Toliyat, "Application of State Space Averaging Method to Sliding Mode Control of PWM DC/DC Converters", presented at conf on IEEE Industry Applications Society, Oct. 1997.

[9] Simon S. Ang and Oliva Alejandro, "Power Switching Converters", Second Edition, Taylor \& Francis, Inc. March 2005.

[10] Jan Jantzen, "Design Of Fuzzy Controllers". Tech report no 98-E 864 (design), 19 Aug 1998.

[11] Fuzzy Logic Toolbox ${ }^{\mathrm{TM}}$ User's Guide, The MathWorks,Inc. 1995 - 2009.

[12] Ghulam Abbas, Nacer Abouchi and Cyril Condemine, "Design and Comparison of Various Analog Controllers for High-Frequency Low-Power DC-DC Buck Converter", 2nd ICIIT 2010, Pakistan, Paper ID B222.

[13] Ghulam Abbas, Nacer Abouchi, Awais Sani, Cyril Condemine, "Design and Analysis of Fuzzy Logic Based Robust PID Controller for PWM-Based Switching Converter", IEEE Transactions on Power Electronics 